\title{
MÍDIA E TRABALHO INFANTIL: CULTURA, REPRESENTAÇÃO E DISCURSO
}

\author{
(Media and childhood's work: culture, \\ representation and discourse)
}

\author{
Vânia Maria Lescano Guerra ${ }^{1}$ \\ (Universidade Federal de Mato Grosso do Sul- UFMS) \\ Rosemere de Almeida Aguero ${ }^{2}$ \\ (Universidade Federal de Mato Grosso do Sul-UFMS)
}

\section{RESUMO}

Esta pesquisa, fundamentada na teoria dos discursos, nos estudos foucaultianos e nas noções dos Estudos Culturais, vem problematizar a construção do discurso sobre o trabalho infantil na mídia de Mato Grosso do Sul (MS), a partir da análise de dez reportagens veiculadas pela TV Morena e pela Rede Globo de Televisão, feitas na região do Pantanal de Corumbá e demais regiões do Estado de $\mathrm{MS}$, cujo tema é a infância em situação de exploração do trabalho.

Palavras-chave: cultura; discurso; trabalho infantil; exploração; mídia.

\section{ABSTRACT}

This research, based on the theory of the discourses, Foucault studies and in notions of Cultural Studies, is due to problematize the construction of the discourse about the childhood's work in the media of Mato Grosso do Sul (MS), from the analyses of ten stories broadcasted

1. Docente da Graduação e da Pós-Graduação em Letras da Universidade Federal de Mato Grosso do Sul, do câmpus de Três Lagoas (MS) e pesquisadora da FUNDECT.

2. Mestre em Letras pela Universidade Federal de Mato Grosso do Sul, câmpus de Três Lagoas (MS) e docente do curso de Letras da Universidade Estadual de Mato Grosso do Sul, câmpus de Jardim. 
by TV Morena and Globo Television network, recorded in the Pantanal of Corumbá and other regions of Mato Grosso do Sul state, whose theme is the childhood in the exploitation of labour.

Key-words: culture; discourse; childhood's work; exploitation; media.

\section{Introdução}

Este artigo, que vem problematizar a construção do discurso sobre o trabalho infantil na mídia de Mato Grosso do Sul (MS), analisa dez reportagens veiculadas pela TV Morena e pela Rede Globo de Televisão, feitas na região do Pantanal de Corumbá e demais regiões do Estado de MS, cujo tema é a infância em situação de exploração do trabalho. No foco analítico dessas reportagens, a subjetivação dos sujeitos é considerada como um fenômeno intermediado por complexas relações sociais, em que estão presentes a história, a cultura, a ideologia e as relações de força que dão origem a discursos disseminados por toda a sociedade.

Esta abordagem, fundamentada na teoria dos discursos, nos estudos foucaultianos e nas noções dos Estudos Culturais, considera o discurso televisivo como uma expressão do exercício de poder na sociedade contemporânea, cujas análises são articuladas a partir de um prisma que se lança ao sujeito, compreendendo-o como uma invenção histórica, produto de árduos e conflituosos acontecimentos discursivos e de interesses originados nos múltiplos lugares da sociedade. O trabalho de análise é feito a partir de recortes, segundo o conceito de Orlandi (1984: 14), para quem o recorte é um "fragmento da situação discursiva".

Da mesma forma, como acreditamos que as produções culturais nos subjetivam, optamos por buscar conhecer as formas como a mídia representa o trabalho infantil. A mídia tem sido considerada um lugar privilegiado de circulação de discursos em nossa sociedade, logo, importante para as construções identitárias, objeto dos estudos discursivos e culturais. Os Estudos Culturais têm investigado os efeitos dos discursos da cultura midiática, as formas 
como o público se apropria dos mass media e como imagens e textos da mídia funcionam dentro da cultura em geral. De acordo com os Estudos Culturais, a cultura da mídia vem auxiliar na constituição hegemônica de certos grupos e projetos políticos. Problematizar as diferenças culturais em contextos políticos, sociais e históricos é tarefa dos Estudos Culturais, a partir do estudo da atualidade e da investigação da multiplicidade de objetos que se pretende abordar. Assim, as questões de raça, etnia, gênero, nacionalidade, orientação sexual, críticas específicas à opressão são importantes contribuições aos Estudos Culturais. Ler politicamente a cultura significa ver como as produções culturais da mídia reproduzem, em suas imagens, sua narrativa. Uma das finalidades deste estudo é discutir alguns discursos dominantes e as relações de poder presentes na sua opacidade.

\section{O discurso midiático: história, infância e proteção}

É pelo e no discurso, como instância de articulação entre o nível linguístico e sua exterioridade, que se opera a construção/ desconstrução de identidades que se constituem nos textos, na história, nas instituições. Identidades são concebidas aqui como movimentos contínuos/descontínuos das relações que sujeitos, comunidades, nações e instituições estabelecem imaginariamente com o real, produzindo uma interface que vem garantir sua circulação e inserção dentro de certas condições sociais, culturais, históricas e discursivas que são, elas próprias, constitutivas daquelas relações (Guerra, 2008: 111-112).

Para Foucault, o valor e o sentido do discurso só podem ser analisados como um efeito histórico, a partir da relação entre o saber e o poder presentes no campo social. Para que se possa compreender, portanto, como um discurso irrompe na sociedade em determinado momento histórico, é necessário estudar não apenas o momento das suas condições de produção, mas especialmente as condições ideológicas e históricas que permeiam esses discursos. A história a servir como objeto de investigação, não é, entretanto, aquela 
das continuidades em progressão ou da reversão à gênese, de uma "racionalidade continuamente crescente" (Foucault, 2002: 5), mas aquela que se identifica com a interrupção, com as descontinuidades, voltando-se para os diversos campos de dispersão.

Por conseguinte, no processo de investigação da constituição dos sentidos discursivos consideramos os elementos históricos, que se originam da forma de nossa sociedade, não apenas implicando o aspecto material, mas considerando o que é institucional em seus aspectos de formação e de estabelecimento de uma ordem social. Nesse sentido, a investigação deve incidir sobre os enunciados, buscando seus modos de dispersão. Em outras palavras, a investigação tem que considerar o "fato de que o discurso não tem apenas um sentido ou uma verdade, mas uma história, e uma história específica que não o reconduz às leis de um devir estranho" (Foucault, 2002:146).

Os discursos analisados ganham significados a partir de uma rede de sentidos constituídos e disponibilizados à análise por meio do interdiscurso, da memória que reconstitui saberes, que retornam nas falas dos entrevistados, e que estiveram presentes em diversos momentos da história deste país. Verifica-se, nos recortes, a reiteração de um conjunto de enunciados que podem ser agrupados em torno de uma tradição discursiva semelhante, de antigos já-ditos retomados em sucessivos discursos. A primeira questão é de onde provêm esses enunciados? A que formação discursiva estão relacionados? Que traços ideológicos estão materializados neles? Tais enunciados são registros de discursos, cujo objeto é a infância, que, se entrecruzados à recente história do nosso país - século XX e início do século XXI -, podem (res)significar o enorme distanciamento entre o universo dos discursos históricos, articulados por meio das instituições nacionais, e o mundo real no qual a criança pobre tem vivido imersa.

A história social da criança aponta para um passado de violação e exploração, que se perpetua na contemporaneidade e está presente nas reportagens. Ariès (1981), pioneiro nos estudos sobre a infância na Europa, problematizou a temática em sua obra, tomando por base dois fios condutores. $\mathrm{O}$ primeiro remete à ausência do conceito de infância, tal qual o conhecemos hoje, durante toda a Idade Média, 
época em que a criança era praticamente invisível aos olhos da sociedade. O segundo aponta para o reconhecimento da infância como período anterior à vida adulta, atribuindo, a partir dos séculos XVII e XVIII, um novo status à criança e à família. Após esse período, a infância passa a ser reconhecida como uma fase de ingenuidade e fragilidade do homem.

O conceito de infância só começou a ser pensado no mundo a partir do século XVI, segundo Ariès. Nesse período, a criança começou a existir. $\mathrm{Na}$ idade Média, um menino de sete anos era reconhecido como um homem, em todos os aspectos, tendo acesso ao mesmo ambiente informacional, vivendo o mesmo mundo intelectual e social e vivenciando todos os comportamentos comuns à cultura. Postman (1999: 31) associa a inexistência da ideia de infância nesse período à "[...] falta de alfabetização, a falta do conceito de educação, a falta do conceito de vergonha - estas são as razões pelas quais o conceito de infância não existiu no mundo medieval”. A alta taxa de mortalidade infantil contribuía também para que os adultos não se envolvessem emocionalmente com as crianças. A ideia comum era de se ter muitos filhos para que sobrevivessem, ao menos, um ou dois.

Continuando a sua análise historiográfica, Ariès (1981) aponta a invenção da imprensa como um período de separação entre adultos e crianças, com a concepção do homem letrado. A partir desse período, a criança, para se tornar adulto, tinha que aprender a ler e escrever, consequentemente, precisava de educação. Desse período em diante, a civilização europeia reinventou a escola, transformando a ideia de infância numa necessidade. Por conseguinte, o conceito de infância desenvolveu-se rapidamente onde havia escolas e onde a instrução era valorizada: crianças e jovens passaram a ser vistos como adultos não formados. O autor observa, ainda, que o modelo de família tomou forma a partir do momento em que se formalizou o conceito de infância. Nesse sentido, o grande evento criador da família moderna foi a invenção e expansão da escolarização formal.

A invenção da infância livresca contribuiu para reprimir a energia dos jovens, obrigando-os a criar condutas inerentes a um bom leitor: senso de individualidade, lógica, capacidade de abstração 
e de adiamento o prazer. Em uma palavra, senso de autocontrole, que se estendeu também aos costumes e práticas sociais e a vergonha foi o mecanismo utilizado para o controle dos corpos. A partir do século XVI começa-se a impor a disciplina rigorosa às crianças, coibindo suas inclinações naturais e concebendo-as como um caráter a ser modulado. O pensamento de Rousseau foi estratégico nessa concepção educadora, contribuindo com a ideia de que a natureza deveria ser subjugada no interesse de se conseguir uma alma purificada. Assim, inúmeras crianças foram submetidas a um regime educacional rigoroso, destinado a torná-las boas.

Ao desenvolver o conceito de infância, a sociedade inventou o segredo e, com ele, um repertório de palavras que não poderiam ser pronunciadas diante das crianças, relacionadas a relações sexuais ou sociais, dinheiro, violência, doença e morte. No limiar de 1850, a infância já era um princípio social em todo o ocidente. Já no Brasil, o conceito de infância e o sentido de proteção só chegou tardiamente. Dessa forma, a história social da infância brasileira identifica-se com "a história da (des)proteção à criança e ao adolescente" (Custódio, 2006: 211). O país apresenta uma longa tradição de exploração ao trabalho infantil, iniciada desde o século XVI, quando as terras brasileiras começaram a ser povoadas e crianças eram trazidas para cá, nas embarcações lusitanas. Durante essas verdadeiras epopeias marítimas, as crianças eram enviadas ao novo mundo trabalhando como grumetes ou pajens, nos grandes navios portugueses, ou como órfãs do rei, mandadas à Colônia para se casarem (Ramos, 2006: 19-54).

Rizzini (2006: 376) afirma que as crianças pobres sempre trabalharam neste país e, em meio a um universo adulto de extremas dificuldades, têm sido obrigadas a se adaptar ou perecer ante os maus tratos, a violência e o sofrimento. Desde os primórdios da colonização do Brasil, a criança trabalhou, ora "para os grandes proprietários de terras como bóias-frias; nas unidades domésticas de produção artesanal ou agrícola; e finalmente nas ruas, para manterem a si e as suas famílias" (p. 377). Como se pode observar, a sociedade brasileira possui uma tradição assentada na exploração ao trabalho de crianças e adolescentes, recrutados por constituírem-se em mão-de-obra dócil 
e barata. O recrutamento, ao longo da história, foi facilitado pelas condições de abandono, de pobreza e pela intensa miséria vivida por grande parte da população. Diante de condições de extrema miserabilidade, os pais eram levados a abandonar cada vez mais os seus filhos, facilitando a ação de uma falsa filantropia interessada na exploração da capacidade produtiva das crianças e adolescentes, e de um Estado que tomou para si as tarefas de educação e saúde das crianças pobres, por meio de políticas públicas e legislações criadas segundo essa ideologia. Enquanto no período Colonial acentuaramse o desvalor e a exploração da infância nas embarcações lusitanas, no período Imperial as ações caritativas da filantropia privada, com seus orfanatos, foram expressivas, ressaltando a situação da massacrante desigualdade entre as crianças da elite e as escravas ou empobrecidas. Assim, no transcurso da história brasileira, a exploração e a desigualdade perpetuaram-se.

Na sociedade escravista, as crianças brancas possuíam escravos aos quais distribuíam ordens aos gritos. As mulatas e negras forras, na primeira metade do século XVIII, também tiveram escravos, muitas vezes entre seus próprios parentes ou meio irmãos (Del Priore, 2006: 12). Dos escravos que desembarcavam no Rio de Janeiro, no início do século XIX, quatro por cento eram crianças. Destes, um terço sobrevivia até os dez anos. Paradoxalmente, apesar de essa ser uma época de profundas contradições sociais, em que coexistiam propostas liberais e escravistas, é nesse período que a infância começa a ser reconhecida, no Brasil, como uma etapa do desenvolvimento humano, a exemplo do que já havia acontecido na Europa. A partir daí, influenciada pelas concepções "[...] do positivismo e do higienismo [produz-se] aparatos de controle e disciplinamento por meio da exploração no trabalho e a institucionalização, legitimadas pelas idéias moralizadoras da salvação do futuro do país" (Custódio, 2006: 210). Na prática, a junção de propostas tão diferentes, como o liberalismo e a escravidão, propiciou o aparecimento de práticas disciplinares e de controle social direcionadas à infância pobre.

A República, em 1889, inaugurou o discurso do crescimento nacional. A ideologia de que o trabalho era a solução para o problema 
do "menor abandonado" e "delinquente" começava a ganhar força. A teoria de que a desestruturação familiar originava criminosos fez que o Estado tomasse para si "[...] as tarefas de educação, saúde e punição para crianças e adolescentes" (Passeti, 2006: 348). A integração do indivíduo à sociedade por meio de contenção à delinquência, tornou-se tarefa do Estado, que também passou a defender a ideologia da família monogâmica e estruturada, dentro de princípios moralistas. A ideologia da preservação da ordem nacional irmanava-se com a da educação estatal obrigatória, fazendo coro ao ideal de integração da criança pelo trabalho. Após a Revolução de 1930, o discurso da educação entra em franca ascensão. A ideologia da época proclama a educação para o trabalho, via institucionalização estatal e visando à criança pobre, como meta do Estado. Toda a legislação que respaldava essa política de disciplinamento visava ao controle das manifestações individuais, consideradas perigosas ao Estado, a partir de três fios condutores. O primeiro tencionava dar uma satisfação aos organismos internacionais do trabalho, representados pela OIT (Organização Internacional do Trabalho), cujos princípios de proteção pediam uma resposta aos governos. O segundo procurava preservar os interesses dos industriais da época, por meio da manutenção de mão-de-obra infantil barata. O terceiro autorizava as instituições beneficentes a utilizarem o serviço das crianças sem limite de idade mínima, reforçando a prática da caridade como instrumento de exploração.

Temos como exemplos dessas legislações a Constituição de 1934, que determinava a proibição ao trabalho de menores de 14 anos sem permissão judicial, e o Decreto $\mathrm{n}^{\circ} 22.042$, de 1932, que determinava também a idade mínima de 14 anos para o trabalho, salvo subsistência individual ou familiar da criança. As ações filantrópicas reproduziam essa forma de controle inaugurando uma rede de escolas direcionadas a crianças abandonadas e delinquentes. A ideologia do trabalho era francamente reproduzida, e crianças passaram a trabalhar mais de doze horas por dia, em ambientes insalubres, sob forte disciplina. Crianças e adolescentes eram o foco de um discurso que enaltecia o trabalho como forma de resgate. 
A constatação dessa política de controle, disciplinarização e docilização dos indivíduos, acompanhada da certeza de que as crianças experimentaram crueldades e violências inimagináveis após sua implantação, remete-nos ao modelo societário foucaultiano, que mostrou que as sociedades modernas, por meio de práticas disciplinares, construíram um sistema de poder baseado no controle e na submissão, com o propósito de tornar os corpos úteis à estrutura social. O fato de esse "preparo" ser conduzido no interior de instituições fechadas, a partir da prática da internação, sob a alegação de abandono, delinquência, libertinagem e mendicância, aproxima-a a sociedade atual definitivamente da sociedade disciplinar de Foucault, demonstrando que a sociedade brasileira também se organizou por meio desse paradigma, criando justificativas para a ação repressiva do poder, baseadas no discurso de regeneração pelo trabalho (Passeti, 2006).

Entre as ditaduras de 1937 e 1945 e o regime militar de 1964 e 1984, as políticas sociais implementadas pelo governo sofrerão franca expansão, com a criação da FUNABEM (Fundação Nacional do Bem-Estar do Menor) e das FEBEM (Fundação do Bem-Estar do Menor). A Política Nacional do Bem-Estar do Menor, em sintonia com a Lei de Segurança Nacional, criará uma rede de correção repressiva, mascarada sob a forma de assistência social, a partir da ideologia autoritária do regime militar. O isolamento como forma de contenção, a disciplina, a moralização e o trabalho para a obtenção da obediência, visando à domesticação das individualidades, eram práticas autorizadas com a finalidade de garantir a segurança nacional, consoante os princípios de "ordem e progresso". Todas as iniciativas, dessa forma, eram voltadas para o controle, a vigilância e a repressão das camadas populares, mantidas sob o rígido controle da ditadura.

O Código de Menores de 1979, construído a partir da Doutrina do Menor em Situação Irregular (Custódio, 2006: 76), mais uma vez legalizará a concepção do abandono e da infração, ratificando as desigualdades e legitimando a cultura do trabalho. Como se verifica, mais uma vez estará ratificada a tendência 
brasileira a considerar o trabalho como redentor da infância pobre e a de fazer da delinquência e do abandono justificativas plausíveis para a exploração ao trabalho de crianças e adolescentes. Por meio desses mecanismos legais, a cultura paternalista do Estado estará legitimada, assim como seu papel assistencialista e a patologização da pobreza, visualizada a partir de uma perspectiva controladora, repressiva e autoritária, como uma verdadeira ameaça à ordem social.

A ideologia social da época pedia por uma infância boa, institucionalmente domesticada, servil aos interesses do Estado. Em busca desse modelo de cidadão e sob o signo da correção e da repressão, perpetuavam-se práticas violentas, legitimadas pela ação paternalista do Estado, "[...] ente responsável pelo controle e distribuição da dor" (Custódio, 2006: 77). Em nome da ordem pública, a ideologia do desenvolvimento e a ideologia da segurança nacional consagraram uma política de repressão e interdição, por meio da imposição da disciplina, que serviu de mote para o controle, a vigilância e a repressão violenta das camadas populares, consagrando castigos, punições e crueldades como práticas educadoras. A cristalização dessa violência, por meio da divulgação da mídia, chamando a atenção da sociedade para os meninos de rua e para um modelo educacional em crise, assim como a emergência de novos movimentos sociais que desafiavam o Estado, requerendo a implantação de políticas públicas de inclusão, promovendo debates, reflexões e construindo propostas, impulsionaram a mudança, na construção de novos direitos à criança e ao adolescente, que representam uma ruptura com o modelo anterior (Custódio, 2006: 211).

Soma-se a essas iniciativas a ação dos movimentos sindicais, como a CUT (Central Única dos Trabalhadores), que, na década de 1980, mobilizou milhares de pessoas em torno da luta pela erradicação do trabalho infantil. A ação desses movimentos de resistência é significativa em toda a história nacional. Conforme Foucault (1977: 91), "Esses pontos de resistência estão presentes em toda a rede de poder", de maneira irregular, ou seja, ocorrem em diversos pontos da sociedade, sob várias formas de enfrentamento. 
A resistência, longe de significar apenas um processo de mobilização nacional, acontece também a partir de pequenas lutas pontuais desenvolvidas no mesmo espaço das relações sociais, no lugar onde o indivíduo se encontra.

Apesar de a ação do poder na exploração ao trabalho infantil ter sido constante desde o século XVI, no Brasil, é possível identificar, no decorrer da história, diversos pontos de resistência. O primeiro seria a desobediência, a malcriação e mesmo as brincadeiras fora de hora, que pontuavam o trabalho cotidiano das crianças operárias nas fábricas e oficinas de São Paulo, no início do século XX e que eram repreendidas violentamente. $\mathrm{O}$ segundo corresponderia à resistência operária, da qual participavam crianças, e que ganhava as ruas ou se fazia presente desde o roubo de peças das fábricas à destruição de equipamentos e greves, também datadas do início do século XX.

Outro ponto estaria na imprensa, que denunciava as condições desumanas de trabalho, mostrando-se particularmente sensível às más condições do trabalho infantil, mobilizando diversos segmentos sociais, e também a crítica da própria imprensa aos pais, acusandoos de gananciosos e exploradores dos filhos. Ainda outro ponto corresponderia à criação de comitês de tendência anarquista, contra a exploração de menores, entre outros. (Moura, 2006: 270-81). Outra forma de resistência identificada com o período do regime militar foram as sucessivas tentativas de fuga das instituições governamentais. Algumas chegaram a ganhar a dimensão de rebeliões, com internos ateando fogo nos pavilhões, gerando mais violência e destruição. Todas as manifestações descritas datam do século XX, entretanto, apesar de esses exemplos estarem circunscritos a esse período, esses pequenos focos de resistência aconteceram em muitos outros momentos da história.

Com a abertura política do regime militar, diversos movimentos sociais mobilizaram-se pedindo a revisão do "Código do Menor". A Constituição de 1988 promoveu o fim da política bipolar, baseada na pobreza e na delinquência, e propiciou a criação do novo Estatuto da Criança e do Adolescente - ECA (Passeti, 2006: 364). A nova lei 
propôs-se protegê-los da família desestruturada, dos maus-tratos, garantindo a educação, alimentação, políticas sociais e bases para a cidadania. Inauguraram-se parcerias entre o Estado e Organizações Não-Governamentais, reduzindo os custos do governo em investimentos sociais. Essa política, além de propiciar a contenção de gastos do Estado, gerou empregos no âmbito privado, liberando os empresários para a nova filantropia. Essa nova modalidade de filantropia é exercitada, contemporaneamente, mediante a redução do pagamento de impostos, o que a coloca num patamar diferenciado da filantropia privada, característica do Império, e da filantropia estatal, inaugurada com a primeira República. E, no início do século XX, a grande prioridade do poder público era garantir o acesso da criança pobre à escola. Na Constituição de 1934, a educação apareceu, pela primeira vez, como direito de todos e dever do Estado. Entretanto, a partir dessa época, gradativamente o Estado aperfeiçoou o controle sobre a educação, tanto na escola quanto na família, transformando os serviços educacionais em serviços penitenciários. Durante o Estado Novo, a educação propunha-se atingir, pela política da governamentalização, toda a sociedade brasileira. Para tanto, instituiu a política do paternalismo assistencial. Após a Constituição de 1988, com a aprovação do ECA, a educação foi enfatizada como elemento essencial na formação do futuro cidadão.

Em suma, a escola, especialmente a partir da década de 1930, passou a ser considerada como redentora da infância e da adolescência pobre, abandonada, imersa na delinquência, na vadiagem/criminalidade. Essa política pública em torno da educação serviu, durante muito tempo, como justificativa para a exploração da força produtiva das crianças e adolescentes, mantidas em instituições e internatos estatais. Apesar de relativamente distantes da época do elogio à disciplina, da ideologia do trabalho como elemento regenerador, essa prática produziu seguidores que ainda hoje estão presentes na sociedade brasileira. Del Priore (2006: 10) ratifica a existência dessa prática, transcrevendo a fala de uma mãe para quem "O trabalho [explica uma mãe pobre] é uma distração para a criança. 
Se não estiver trabalhando, vão inventar moda, fazer o que não presta. A criança deve trabalhar cedo".

\section{Uma análise das falas da mídia televisiva sob o olhar discursivo-culturalista}

O trabalho de enquadramento das memórias coletivas é, certamente, um dos ingredientes mais relevantes para a perpetuação do tecido social, cultural e das estruturas institucionais de uma sociedade Assim, diante de um texto, o leitor pode construir uma rede de significações, que já vem sendo tecida há muito tempo, cujos sentidos são produzidos historicamente e ideologicamente interpretados como naturais. "Guiado pela preocupação de ora manter, ora modificar as fronteiras sociais e alimentado de material fornecido pela história, o trabalho de enquadramento reinterpreta o passado em função de combates do presente e do futuro" (Guerra, 2008: 113).

Como se vê, em pleno século XXI, há pessoas que ainda defendem uma ideologia implantada ao final do século XIX, segundo a qual o trabalho constitui-se na melhor escola. É importante considerar os fatores históricos já apontados, uma vez que eles são determinantes na construção dos discursos em torno da exploração ao trabalho infantil, que irrompem na contemporaneidade sob certas condições. Desse modo, devem-se entender os discursos analisados neste estudo como representativos da contemporaneidade, resultando de um complexo de ideologias presentes num conjunto de práticas discursivas que se perpetuaram por todo o século XX, chegando aos dias atuais.

$\mathrm{Na}$ contemporaneidade, o trabalho da criança e do adolescente como um mecanismo disciplinador ainda é reconhecido, em muitos pontos do país, como elemento que afasta a criança das más companhias e do perigo das ruas. Um exemplo desse fato está na $6^{\text {a }}$ reportagem, na fala do feirante Agnaldo, que começou a trabalhar aos 15 anos e defende: 
$6^{\text {a }}$ reportagem - Adolescentes Mirins e Trabalho Infantil nas Feiras Livres"

- O melhor remédio, hoje em dia, é estar no trabalho! Melhor do que na rua! O que a gente vê na rua!

Emerge da fala transcrita o interdiscurso, sob forma de uma memória discursiva ativada, em que estão alojados vários já-ditos que retornam às palavras do entrevistado, como elementos précontruídos. A memória, nesse discurso, irrompe na atualidade do acontecimento (Foucault, 2002: 28). O acontecimento vincula-se ao momento da entrevista. $\mathrm{O}$ enunciado do feirante pertence a um domínio de memória que o associa aos discursos do século passado, que enalteciam o trabalho como elemento regenerador da infância pobre. O enunciado recortado, assim, como um lugar de memória discursiva, "reflete as representações sociais sobre aquilo que a sociedade aprendeu a pensar" da infância pobre (Fonseca-Silva, 2007: 29)

Pêcheux (2002), quando define o discurso como "estrutura e acontecimento", postula o acontecimento como ponto de encontro de uma atualidade e uma memória. A memória remete-nos aos esquecimentos número um e dois, de Pêcheux, presentes nos sentidos constituídos pelo feirante. O esquecimento número um, da instância do inconsciente, faz que Agnaldo, sem se dar conta, reproduza a ideologia dominante do século XX. O esquecimento número dois, da ordem da enunciação, permite que se forme em suas palavras uma série de famílias parafrásticas, a partir dos dizeres historicamente fundamentados no último século. É a ideologia do bom menino, necessário ao Estado, que volta nas palavras do feirante, que cresceu ouvindo esses ideais de ordem e progresso nacional, que agora são resgatados no seu discurso. Outros exemplos dos esquecimentos número um e dois, de Pêcheux (1988), encontram-se nos seguintes fragmentos: 


\section{$4^{\text {a }}$ Reportagem: Crianças Trabalhando nos Lixões em Campo Grande - MS}

[...] Então é um debate que tem que se fazer, dentro da sociedade, né, para que a gente possa entender que o lugar da criança é na escola! $5^{\text {a }}$ Reportagem:Imagens de Crianças em Várias Situações de Trabalho e Reportagem de Convenção Contra o Trabalho Infantil, Realizada em Campo Grande - MS

E o prejuízo para o Brasil, pois elas trabalham e deveriam estar na escola?

Nesses recortes transcritos, podemos identificar simultaneamente os dois esquecimentos. O primeiro, de natureza ideológica, presente na retomada, por parte dos entrevistados, de antigos discursos, provenientes do início do século XX - "Lugar de criança é na escola!” - recuperados pela memória discursiva. O segundo, da ordem da enunciação, está explícito no segundo recorte, em que o sujeito retorna por meio de reformulação parafrástica ao mesmo dizer sedimentado socialmente. Note-se que nesse processo parafrástico, a significação sofre deslizamento, mantendo, entretanto, a mesma filiação de sentidos. Nas formulações recortadas, o deslizamento ocorre quando há o apagamento de marcas linguísticas, modalizadoras, tais como "segundo X", "Y diz que", do que poderia ser enunciado sob forma de discurso relatado. O que ocorre é uma retomada de outro discurso, enunciado de forma a parecer inédito, anulando todo o processo de formação. Nos enunciados recortados, portanto, reconhecemos o mesmo domínio de memória, identificada em posições semelhantes dos sujeitos que retomam e repetem a mesma formulação: "Lugar de criança é na escola!”; “[...] elas trabalham e deveriam estar na escola!”.

Esses sentidos também podem ser interpretados a partir dos dois eixos de Courtine (1984), referentes ao interdiscuso - o eixo vertical do pré-construído, da instância da memória; e o intradiscurso - eixo horizontal, que se identifica com o que está sendo dito, em 
dado momento. Para o teórico (Courtine, 2006: 90-2), no domínio da memória, encontramos sempre o que poderíamos chamar de "formulações de origem". Durante o trajeto complexo da formação discursiva, elas se transformam, entrecortam-se e ressurgem. O que na arte literária poderíamos entender como plágio aqui é uma prática perfeitamente legítima, porque os sujeitos discursivos são outros e suas posições como sujeitos não são as mesmas: na $4^{\mathrm{a}}$ reportagem, a formulação pertence à chefe da DRT; na $5^{\mathrm{a}}$, ao senador Cristóvão Buarque. É por meio desse trajeto, das repetições e da paráfrase, que o discurso funciona, portanto, como lugar de memória.

Nesses já-ditos, reconhece-se a ideologia dos discursos governamentais do final do século XIX (circunscritos à República Velha) e século XX (ditadura Vargas e regimes militares), em torno da regeneração pelo trabalho. A ideologia do trabalho como solução para o problema do menor pobre, abandonado e delinquente, conforme visto, emergiu em discursos inaugurados com a Primeira República, perpetuando-se após a Revolução de 1930 e ganhando força com o Regime Militar, até nossos dias:

\section{$4^{\text {a }}$ Reportagem: Crianças Trabalhando nos Lixões em Campo Grande- $M S$}

[...] Apesar dos programas de incentivos para manter as crianças na escola, muitas saem de casa, pela manhã, para ajudar na renda familiar! [...] - A DRP vem fazendo essa fiscalização, mas, veja bem, é complicada essa questão do Trabalho Infantil. Muitas vezes a própria família não aceita que ela... que a criança não trabalhe...

\section{$9^{a}$ Reportagem: Exploração do Trabalho Infantil nas Carvoarias II}

[...] A delegacia Regional do Trabalho já fechou dezenas delas (carvoarias), mas reconheceu que muitas crianças são forçadas ao trabalho, pelos próprios pais!

\section{Reportagem: Exploração do Trabalho Infantil nas Carvoarias II}


Repórter TV Morena: Os vales-cidadania, em atraso, trouxeram a Eliane de volta ao trabalho. Ela estuda à tarde e passa as manhãs na carvoaria! Eliane fala ao repórter: - É por causa que o dinheiro não veio! Eu tenho que ajudar o pai! [...]

Repórter TV Morena: Outras crianças passam a metade do dia ajudando os pais...

Perpetua-se, portanto, nos discursos contemporâneos recortados, a ideologia do trabalho dignificante, ratificando velhas tradições fundamentadas não apenas na necessidade de manutenção do núcleo familiar, mas na disciplina, no controle, na repressão e na submissão. Ratifica-se, de igual modo, a visão distorcida do pequeno herói, ajudante da família, que solitariamente se constrói. Tal ideologia, fruto do individualismo liberal, segundo Custódio (2006: 216), integra a política de instituições orientadas por velhas tradições, cujos discursos valorizavam a criança que ajudava a família, na condição do indivíduo heróico. As crianças que se tornam herdeiras dessa concepção ideológica, são socializadas, desde a mais tenra idade, a aceitar seu lugar, numa sociedade estratificada, onde lhes são reservadas funções subalternas, conforme a fala do menino pantaneiro:

\section{$2^{a}$ Reportagem: Crianças que Catavam Iscas vão à Escola pela Primeira Vez}

- Estudando, eu quero ser um mecânico, né!

São poucos os que aspiram a uma profissão mais reconhecida socialmente:

$2^{a}$ Reportagem: Crianças que Catavam Iscas vão à Escola pela Primeira Vez

- Para ser médico! Para sair dessa vida!

A partir dessa visão ideológica do trabalho dignificante, perpetua-se a tolerância à exploração infantil, reprodutora das desigualdades sociais e da omissão do Estado e da sociedade. Para 
Custódio (2006: 215), a superação do trabalho infantil precisa da desmistificação do trabalho na infância, que implica reconhecer o ócio como dimensão contemplativa da vida e necessário ao desenvolvimento de todos os sujeitos. Segundo Rizzini (2006: 386), os motivos pelos quais as crianças trabalham, no Brasil, nem sempre coincidem com os alegados por elas. A maioria é vitimada pela miséria. Embora reconhecido como degradante, tanto pelas próprias crianças, quanto pelos pais, o trabalho infantil ainda é necessário à manutenção de muitas famílias pobres. Essa situação não é diferente em Mato Grosso do Sul:

\section{$2^{\text {a }}$ Reportagem: Crianças que Catavam Iscas vão à Escola pela Primeira Vez}

Ir para a escola trouxe de volta o sonho de aprender a ler e a escrever! - Para quê? Pergunta a repórter. - Para ser médico! Para sair dessa vida!

\section{9a Reportagem: Exploração do Trabalho Infantil nas Carvoarias II}

[...] Com o Projeto elas podem ganhar bem mais, mandando os filhos para a escola! O governo promete pagar 50 reais para cada criança que trocar a fumaça das carvoarias pela escola do ensino de $1^{\circ}$ grau.

O repórter pergunta à mãe do menino carvoeiro: - O dinheiro que a senhora vai ganhar, pelo estudo dos seus filhos, compensa?

- Compensa! Melhor do que eles ficarem aqui, trabalhando! É pior aqui! Não dá futuro para ninguém!

Pesquisas mostram que são as famílias mais pobres que recorrem ao trabalho das crianças. Assim, 23\% das crianças entre dez e quatorze anos, oriundas de famílias que ganham até meio salário mínimo mensal por pessoa, trabalham (Rizzini, 2006: 387). Quando a renda familiar aumenta, a taxa de atividade infantil diminui, entretanto não é apenas a necessidade que leva o menor ao trabalho. $\mathrm{Na}$ adolescência, fatores individuais, como ter o próprio dinheiro, ser independente ou buscar melhores oportunidades e qualificação, 
somam-se a fatores culturais, como a ideologia de que a criança pobre tem que trabalhar:

\section{$3^{\text {a }}$ Reportagem: Crianças Vendedoras de Jornais no Trânsito de Campo Grande I}

[...] Aos doze anos, Douglas já estava na rua, garantindo o próprio dinheiro. A rotina às $5 \mathrm{~h}$ da manhã, só termina às $9 \mathrm{~h}$. Com o salário o menino compra o que precisa e divide e ajuda a mãe.

\section{$6^{\text {a }}$ Reportagem: Adolescentes Mirins e Trabalho Infantil nas Feiras Livres}

[...] Fernanda tem 16 anos e trabalha no Fórum de Campo Grande. É uma das 37 adolescentes que conseguiram emprego no Poder Judiciário. Ela ganha 145 reais por mês... O mesmo salário do colega Márcio! Ele trabalha no setor administrativo do Poder Judiciário; quer adquirir experiência profissional para ter uma vida melhor! Márcio, diz: - Ainda mais trabalhando no Poder Judiciário! O pessoal, lá fora, respeita muito o Poder Judiciário! Referência ótima, aqui!

Repórter TV Morena: Mas, muitos adolescentes começam a batalhar pelo próprio dinheiro ainda criança, situação que esbarra na lei.

Como se pode observar, a expectativa distorcida da ascensão social em decorrência do trabalho é uma ideologia ainda recorrente entre adolescentes pobres: Marcio "trabalha no setor administrativo do Poder Judiciário; quer adquirir experiência [...] para ter uma vida melhor [...]”. Custódio (2006: 215) alerta que uma valorização positiva do trabalho infantil poderia evidenciar determinadas condições de exploração, invisíveis ao senso comum. Nesse sentido, o estudioso aponta sete mitos culturais que tentam justificar a exploração ao trabalho infantil, difundidos na sociedade: a) é melhor trabalhar do que roubar; b) é melhor trabalhar do que ficar nas ruas; c) o trabalho da criança ajuda a família; d) lugar de criança é na escola; e) é melhor trabalhar do que usar drogas; f) trabalhar não faz mal a ninguém; g) trabalhar desde cedo acumula experiência para trabalhos futuros (cf. Custódio, 2006: 214). 
O autor aponta, ainda, a insubsistência desses mitos, demonstrando o lado perverso da legitimação dessa exploração, quais sejam: a) dificuldade de acesso, permanência e frequência, da criança, à escola; b) evasão precoce; c) baixo rendimento escolar; d) a reprodução da exclusão educacional; e) reprodução do ciclo gerador de pobreza, f) ausência de pagamento ou pagamento de salários ínfimos; g) a precarização das relações de trabalho; h) o reforço da dependência econômica da família ao trabalho da criança; i) a substituição da mão-de-obra adulta, pela infantil e, em conseqüência, o aumento do desemprego adulto; j) a desmobilização social; 1) o isolamento da criança e do adolescente; m) a legitimação da omissão do Estado; n) o reforço da cultura patriarcal e machista; o) a transferência da responsabilidade do adulto para a criança; o) o prejuízo ao desenvolvimento físico e psicológico da criança, assim como a violação dos seus direitos fundamentais; apenas para citar alguns dos males.

O trabalho na infância e na adolescência é, dessa forma, a principal causa da evasão de crianças e adolescentes da escola. Muitos, em decorrência das longas jornadas, acabam empurrados para cursos noturnos, a que chegam cansados, aumentando as estatísticas de evasão. É o que se constata na $7^{\mathrm{a}}$ reportagem:

\section{$7^{\text {a }}$ Reportagem: Crianças Vendendo Jornais no Trânsito I}

[...] Repórter TV Morena: Um grupo de crianças ou adolescentes trabalham para um mesmo homem. São 12 ou 13 ... todo mundo do mesmo jeito! Todos estudam! Alguns reclamam do sono, à noite, quando vão à escola! Às vezes, algum dia... Não é todos os dias! Esses casos não são isolados. A Delegacia do Trabalho recebe denúncias... Em média, 20 denúncias de trabalho, por mês... 70\% é procedente!

Não se pode negar que, no mercado brasileiro, a procura por mãos pequenas e ágeis, corpos obedientes e pouco exigentes, a exemplo do que acontecia a São Paulo, recém-industrializada, no início do século XX, ainda é muito grande. A esse respeito, Rizzini (2006: 388) explica que "empregadores na agroindústria elogiam a paciência e o cuidado 
das crianças na perigosa e insalubre tarefa de espalhar agrotóxico nas plantações”. Afirma ainda que somente as crianças podiam "catar restos do minério cassiterita nos garimpos”, uma vez que a tarefa era realizada "debaixo de uma máquina escorada por troncos".

Nas condições descritas, vê-se que a preferência pelo trabalho infantil ainda é grande em todo o mercado nacional, apesar das campanhas e mobilizações contrárias em todo o país; entretanto essa demanda acontece pelo fato de as crianças trabalharem muitas horas sem reclamar, alijadas dos direitos trabalhistas e percebendo um terço do valor pago aos demais trabalhadores, sem benefícios sindicais. Perdura, portanto, na contemporaneidade brasileira, a ideologia do taylorismo (Moura, 2006: 285), cuja prática se fundamenta em extrair do trabalho o máximo de rendimento possível. Essa realidade também é comum em Mato Grosso do Sul, particularmente na região de Ribas do Rio Pardo, onde, de acordo com a $8^{\mathrm{a}}$ e $9^{\mathrm{a}}$ reportagens, encontramos famílias inteiras exploradas por empresários inescrupulosos:

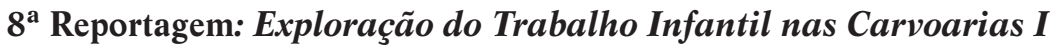 Repórter TV Morena: A mão-de-obra infantil nas carvoarias de Mato Grosso do Sul é hoje um retrato negro do Estado! O setor explora}

cerca de 2.500 crianças no trabalho sobre-humano. Walfrido, de 13 anos, com o irmão de 14 empilha, por dia, cinco toneladas de madeira! Ana Lúcia, de 6 anos, enfrenta o risco de queimar as mãos, na hora de rebocar os fornos e Leandro, de 8 anos, fica o tempo todo embaixo de muita poeira, para ajudar o pai no transporte do carvão!

\section{9a Reportagem: Exploração do Trabalho Infantil nas Carvoarias II}

[...] Repórter TV Morena: Por trás da fumaça vivem os pequenos carvoeiros! Eliton tem 14 anos e trabalha 12 horas por dia. Ganha 25 reais, por mês, para carregar a lenha que vira carvão, e para cobrir de barro o forno em brasa! Só no Município de Ribas do Rio Pardo - MS, a PROMOSUL cadastrou 163 crianças, de 7 a 14 anos. Metade delas está fora da escola! 
Outra realidade nos discursos da $8^{\mathrm{a}}$ reportagem assemelha-se à situação de exploração nas vilas operárias pernambucanas, entre os anos de 1930 e 1950 (Rizzini, 2006):

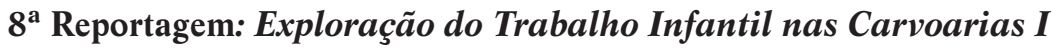 [...] Apesar do esforço e risco eles não recebem salário, e sim comida, uma forma que os empreiteiros usam para complementar o salário dos pais, que vêm trabalhar na carvoaria, sempre em família. Além da situação de miséria, as crianças ficam fora da escola!}

Da mesma forma como ocorria em Pernambuco, onde famílias inteiras eram recrutadas por agentes para os trabalhos nas fábricas (cuja condição era ter menores para complementar a "cota" e conseguir uma casa melhor na vila), em Mato Grosso do Sul os carvoeiros também trabalham em família, nas carvoarias: "[...] eles não recebem salário, e sim comida, uma forma que os empreiteiros usam para complementar o salário dos pais, que vêm trabalhar na carvoaria, sempre em família". Deleuze (1992: 224) aponta a construção de vilas, próximas ao local de trabalho, como um dos mecanismos de sujeição e controle do trabalhador, caracterizado pelo endividamento e confinamento, prática comum nas sociedades modernas. Essas são as condições a que se submetem muitos trabalhadores no Estado. Por meio do pagamento de baixos salários, forçam-se as famílias a utilizar a maior parte dos seus membros no trabalho. As condições encontradas por essas famílias de trabalhadores comparam-se, de igual modo, às das fábricas paulistas do início do século XX, em que coexistiam a má alimentação, o ambiente insalubre, o autoritarismo permeando as relações trabalhistas, além de jornadas longas, que duravam entre doze e quatorze horas diárias. Essas são também as condições identificadas no discurso do menino carvoeiro de Ribas do Rio Pardo (MS):

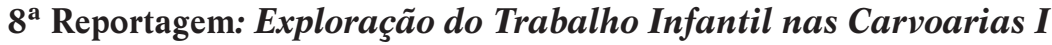

Além da situação de miséria, as crianças ficam fora da escola!

- Nem um dia a gente fica parado... é de domingo a domingo! Diz um menino carvoeiro. 
As jornadas de trabalho excessivas, a exemplo do que se observa nesse recorte, eram comuns para crianças trabalhadoras das indústrias de São Paulo, em 1911. O esforço contínuo e intenso, com jornadas que variavam entre doze e quatorze horas, "[...] com intervalos reduzidos e sem descanso semanal" (Moura, 2006: 270), acabava por debilitar e vitimar muitas crianças. Na contemporaneidade, em muitos estados, conforme comprovam os discursos articulados neste estudo, as crianças continuam a trabalhar sem receber qualquer tipo de remuneração, na condição de ajudantes dos pais, com o intuito de aumentar a renda familiar. Isso está explícito na $3^{\mathrm{a}}$ reportagem: "Com o salário o menino compra o que precisa e divide e ajuda a mãe."; na $4^{\text {a }}$ reportagem: "[...] é que trabalhavam em regime de escravidão pelo menos 50 mil crianças e adolescentes, no Estado.", "[...] crianças recolhendo restos no 'lixão municipal', para ajudar os pais no sustento da família."; na $8^{\text {a }}$ reportagem: "Ana Lúcia, de 6 anos, enfrenta o risco de queimar as mãos, na hora de rebocar os fornos e Leandro, de 8 anos, fica o tempo todo embaixo de muita poeira, para ajudar o pai no transporte do carvão!", "Apesar do risco eles não recebem salário, e sim comida, uma forma que os empreiteiros usam para complementar o salário dos pais, que vêm trabalhar na carvoaria, sempre em família.”, entre outros recortes. Assim, a exploração ao trabalho infantil, apesar de todas as políticas públicas implantadas, ainda é uma realidade nacional.

Além de mostrar a inscrição dos sujeitos das entrevistas na história, materializada por meio da ideologia que perpassa todos os seus dizeres, torna-se importante compreender que os discursos proferidos são produtos dos sujeitos inscritos em determinadas posições sociais. São essas posições que determinam, dentro das entrevistas, as relações de poder e dão uma identidade ao locutor. Uma vez que os discursos presentes nas entrevistas estão determinados pela história e pela ideologia, é necessário analisar essas relações sociais para entender por que os sujeitos se manifestam desta ou daquela maneira, atribuindo sentidos aos seus discursos. Para Gregolin (2007), a mídia realiza esse espetacular trabalho de mesclar sentidos, 
de sobrepor imagens, de produzir um mosaico de emoções e valores, de ideias e sentimentos.

Um outro discurso, também bastante recorrente nos dados analisados, identificável com a invenção da imprensa no século XVI e a partir da reinvenção da escola pela civilização europeia, é o discurso da escola ou da educação. No Brasil, esse discurso ganhou ascensão a partir de 1930 e, ainda hoje, coexiste como forma de redenção à situação da criança pobre:

\section{$1^{\text {a }}$ Reportagem: Crianças Catadoras de Isca no Pantanal de MS}

[...] José Henrique, 10 anos, cata isca desde os sete anos. Nunca foi à escola!

[...] No isolamento do Pantanal, é assim que muitas crianças crescem. Trabalham desde cedo, não tem certidão, não sabem o que é direito à educação.

[...] - De repente a gente não tem uma solução com a rapidez que o caso requer, mas temos que buscar alternativas e vamos ter que encontrar uma fórmula, nem que seja uma escola flutuante para que possa atender essas crianças... que elas tenham acesso à educação!

$2^{\text {a }}$ Reportagem: Crianças que Catavam Iscas vão à Escola pela

\section{Primeira Vez}

[...] William Waac (Rede Globo): Em maio de 2004 você viu aqui, no "Jornal da Globo", crianças no Pantanal que viviam a catar iscas, arriscando-se na água de um rio e nem sabiam o que era uma escola! Cristiane Pelagio (Rede Globo): Hoje nós temos o prazer de mostrar as mesmas crianças que catavam iscas, indo à escola, graças a uma bem sucedida parceria entre o poder público e a iniciativa privada! [...] De casa em casa, o transporte escolar vai apanhando os alunos que só agora começam a entender o significado da educação!

[...] Hoje, o esforço deles é para se acostumar à vida escolar! Com cuidado as letrinhas são desenhadas e vão ganhando um sentido! 
[...] Brasileiros que não tinham acesso à educação e tudo para eles é novidade! Têm um caderno, um lápis, uma borracha, não há limite de idade para começar aprender! Ana Claudia tem vinte anos de idade; só agora está sendo alfabetizada!

[...] Ir para a escola trouxe de volta o sonho de aprender a ler e a escrever!

$3^{\text {a }}$ Reportagem: Crianças Vendedoras de Jornais no Trânsito de Campo Grande I

O emprego é um compromisso que ele ainda divide com o tempo que ele dedica aos estudos. Douglas comenta:

- Trabalho de manhã e estudo de tarde e trago meu material para o serviço, que daqui, quando saio, já passo no colégio, já faço meu trabalho.

$4^{\text {a }}$ Reportagem: Crianças Trabalhando nos Lixóes em Campo Grande - MS

[...] Apesar dos programas de incentivos para manter as crianças na escola, muitas saem de casa, pela manhã, para ajudar na renda familiar! [...] Então é um debate que tem que se fazer, dentro da sociedade, né, para que a gente possa entender que o lugar da criança é na escola!

$5^{\text {a }}$ Reportagem:Imagens de Crianças em Várias Situações de Trabalho e Reportagem de Convenção Contra o Trabalho Infantil, Realizada em Campo Grande - MS

[...] E o prejuízo para o Brasil, pois elas trabalham e deveriam estar na escola?!

6 a Reportagem: Adolescentes Mirins e Trabalho Infantil nas Feiras Livres

[...] Para entrar aqui, [freqüentar o Instituto Mirim] eles precisam estudar!

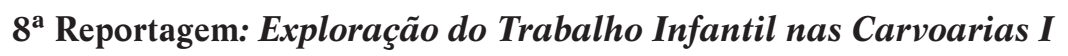
[...] Através de um convênio com o Governo Federal e o estado, as duas Instituições começam a cadastrar famílias num programa que vai dar dinheiro para botar os filhos na escola! 
[...] Para cada criança que freqüentar a escola, a família receberá meio salário mínimo, por mês! O Programa se destina às crianças, na faixa etária dos 7 aos 14 anos. Nessa primeira fase, o Programa vai atingir mil crianças que ficarão livres da exploração nas carvoarias e reconquistarão o direito de estudar!

Observa-se, nas formulações grifadas, a presença do interdiscurso, com base no que Courtine denomina "material discursivo original” (2006: 69), reconhecido aqui sob forma do discurso da educação. Note-se que esses discursos são produzidos no interior de um mesmo sistema de formação discursiva (Foucault, 2002: 122). Esses enunciados formam sequências discursivas assentadas sobre o fio de um mesmo discurso, cuja memória irrompe na atualidade dos acontecimentos, motivo pelo qual se faz necessário confiar na voz de Foucault (2002: 111), quando afirma que "[...] não há enunciado que, de uma forma ou outra, não re-atualize outros enunciados”. Embora nos recortes encontremos formulações diferentes, estas manifestam a mesma posição dos sujeitos: "lugar de criança é na escola!” São sentidos que estão fixados na memória social, como lugares de memória discursiva, que "indicam, difundem, sedimentam e legitimam modos de pensar da sociedade na qual operam” (Fonseca-Silva, 2007: 33).

Reconhece-se nesses discursos, ainda, a heterogeneidade constitutiva, no sentido que Authier-Revuz (1990) atribui ao termo. Articulando o conceito dialógico de Bakhtin, Authier-Revuz mostra que nesses discursos há a existência do outro, presente na superfície discursiva, por intermédio de uma forma não-marcada, em que $o$ outro é dado a conhecer sem uma forma unívoca. Desse modo, o outro não é revelado explicitamente, mas está lá, presente no discurso. O outro, nos enunciados recortados, presentifica-se, historicamente, no discurso citado por Moura (2006: 281), originário no ano de 1917, na Câmara dos Deputados, em São Paulo, proferido por um dos parlamentares, que reivindicava: "O lugar desses menores é a 
escola!”. A partir daí, como nos ensina Courtine (2006: 92), houve um apagamento das formas sintáticas do discurso relatado, mas ficou preservada a formulação original sobre a qual se assentam as outras formulações dos recortes, interligadas por meio de mecanismos linguísticos de ligação ou de encadeamento. Esses encadeamentos deram origem aos discursos recortados nas entrevistas, resgatados, no acontecimento, pela "memória coletiva” (Gregolin, 2007: 45). Numa outra leitura, pode-se reconhecer também a existência de uma "heterogeneidade reconhecida", na proposição de Coracini (2003), revelada apenas aos interlocutores que conseguem identificá-la nesses discursos.

O discurso em favor da educação ganhou força, neste país, à medida que vozes se ergueram contra o trabalho infanto-juvenil, na perspectiva do sério comprometimento que causava à saúde de crianças e adolescentes. Estudos datados de 1910 e 1920 na cidade de São Paulo já verificavam a necessidade de proteção à vida e à saúde do trabalhador menor. Embora desde o ano de 1917 o cidadão Cazemiro da Rocha já argumentasse em sessão da Câmara dos Deputados, em São Paulo, que "O lugar desses menores é a escola" (Moura, 2006: 281), a manutenção da criança pobre na escola, foi uma das soluções encontradas pelo Estado para o treinamento moral, o disciplinamento e o controle da população pobre, encarada como uma patologia social. A partir dessa ideia, promoveu-se uma resposta assistencialista sob forma de práticas de vigilância, controle, repressão e autoritarismo, por parte do Estado. Encarada desse modo, a ideologia de se manter a criança na escola encarnava a idéia de uma infância vista como problema social, como objeto de intervenção do Estado, por meio de uma escola comprometida com os ideais de segurança nacional.

Hoje, após a promulgação do ECA, utilizam-se esses velhos discursos como frases de efeito, cristalizados e incansavelmente repetidos por vozes autorizadas e pelos discursos políticos proferidos por agentes do poder público. Agravante é o fato de que esses chavões, incansavelmente proferidos, trazem em si a concepção de ocupar todo o tempo que a criança possui, na perspectiva de um tempo ocioso: 


\section{$2^{\text {a }}$ Reportagem: Crianças que Catavam Iscas vão à Escola pela Primeira Vez}

[...] Vinte e seis crianças moram na escola, no regime de semi-internato. 10 Reportagem: Exploração do Trabalho Infantil nas Carvoarias II

[...] Isso acontece porque a principal exigência do Convênio não saiu do papel! As crianças deveriam passar o dia inteiro na escola! Faltam professores e funcionários, para que as escolas funcionem em período integral!

Essas características remetem-nos novamente ao pensamento de Foucault, a partir da ideia do controle do tempo e do espaço, usados como mecanismos para a docilização e disciplinarização dos corpos, no contexto da sociedade do panoptismo.

Com o objetivo de esclarecer as críticas sobre um suposto "idealismo cultural", tão reducionista quanto qualquer outro, Hall (1997: 33) pondera que toda prática social tem condições culturais ou discursivas de existência. As práticas sociais, à medida que dependem do significado para funcionarem e produzirem efeitos, situam-se “dentro do discurso", são “discursivas”. Diante disso, nos discursos das entrevistas problematizamos a construção do discurso da nova filantropia brasileira, sob forma de programas sociais firmados entre o governo e o empresariado:

\section{$2^{a}$ Reportagem: Crianças que Catavam Iscas vão à Escola pela Primeira Vez}

Cristiane Pelagio (Rede Globo): Hoje nós temos o prazer de mostrar as mesmas crianças que catavam iscas, indo à escola, graças a uma bem sucedida parceria entre o poder público e a iniciativa privada!

Além de possibilitar a diminuição de investimentos do governo no setor, a nova filantropia ainda se mostra uma fonte segura de geração de empregos para funcionários especializados, como 
psicólogos, assistentes sociais, educadores, entre outros, contratados na condição de investimento social, em torno da criança carente. Essa terceira forma de filantropia (a primeira foi a filantropia privada e a segunda, a estatal) está condicionada, entretanto, ao não-pagamento de impostos ao governo. Desse modo, a criança pobre continua sendo alvo de interesses do empresariado e do Estado, articulados em torno de uma troca de favores. O objetivo dissimulado nas entrelinhas permanece, todavia, o mesmo, estando circunscrito a conter a sua transformação em criança infratora. Perpetua-se o espetáculo das compaixões, sob uma nova roupagem, inaugurado pelas burocracias públicas e privadas, no século XIX, com o abandono de crianças nas rodas dos expostos e o recolhimento de meninas pobres em instituições religiosas (Passeti, 2006: 350), e com o caráter filantrópico dado pelos empresários à exploração da força produtiva dos pequenos operários, em São Paulo, no início do século XX (Moura, 2006: 275).

\section{Mídia e trabalho infantil: a ideologia da (des) proteção...}

As análises empreendidas aqui vêm homologar que os sentidos, longe de estarem cristalizados, acompanham o momento histórico e os grupos que os produzem e interpretam, de acordo com as condições sócio-históricas. É assim que a mídia televisiva, paradoxalmente, embora queira passar uma imagem de distanciamento do poder, quando enfatiza discursos contrários ao trabalho infantil, acaba por perpetuar, por meio de outras enunciações que recorta e veicula, a ideologia do aparelho estatal, articulando vozes que aplaudem o trabalho como elemento regenerador e atualizando frases de efeito, que reivindicam “toda criança na escola!", chavões provenientes de velhos discursos incansavelmente repetidos por vozes autorizadas de políticos e agentes do poder público.

O lugar da produção, longe de ser pacífico, é um campo fecundo, ativo, de lutas pelo poder, sucessivas disputas e batalhas discursivas pelo controle e domínio dos discursos. Essas práticas 
são regulamentadas, controladas, submetidas a uma ordem do discurso, que organiza o que pode e deve ser dito em determinado contexto histórico. Já que a construção do saber se dá a partir da interlocução de diferentes vozes, este estudo pode ser visto como uma oportunidade de reflexão sobre algumas práticas discursivas que dialogam na sociedade contemporânea. Temos convicção de que as políticas sociais voltadas para crianças e relacionadas à ampliação de oportunidades ou conquista de direitos humanos precisam considerar os aspectos materiais e simbólicos que estruturam a família em grupos populares, tendo em mente o papel do grupo doméstico na construção da identidade dos sujeitos sociais.

Tem-se verificado que o conteúdo atribuído ao trabalho é diverso, nem sempre representando uma condição negativa. Ele se reveste, muitas vezes, de um valor moral positivo para a construção da pessoa. Problematizar a forma como o trabalho se apresenta nesse universo foi o intuito deste ensaio e assim a afirmativa sobre o desejável teor culturalmente adequado das políticas públicas não implica adotar qualquer posição de imobilismo político e de respeito acrítico aos valores sociais abraçados por determinados grupos. Isso significa apenas ressaltar a importância de conceber políticas que contemplem as visões de mundo que destoam de pressupostos que se querem hegemônicos. E nessa perspectiva de se construírem propostas de combate ao trabalho infantil, deixamos nossas reflexões: ao se questionar a lógica que justifica o trabalho das crianças para os pais e para elas próprias, é possível obter êxitos na erradicação do trabalho infantil. É preciso pensar, ainda, como fica claro, que o trabalho infantil não decorre, simplesmente, de uma falsa consciência do papel do trabalho na sociedade, como se essa falsa consciência não repousasse sobre uma estrutura material que a constitui e alimenta...

Recebido em: abril de 2010 Aprovado em: maio de 2010 vguerra1@terra.com raaguero@gmail.com 


\section{Referências Bibliográficas}

Ariès, Philippe. História social da criança e da família. Trad. Dora Flaksman. 2.ed. Rio de Janeiro: LTC, 1981.

Authier-Revuz, Jacqueline. Cadernos de Estudos Lingüísticos, Campinas: UNICAMP, n.19, 1990, p.25-42.

Brasil. Decreto ${ }^{\circ}$ 22.042, de 03 de novembro de 1932. Estabelece as condições de trabalho dos menores na indústria. Coleções de Leis do Brasil. Poder Executivo, Rio de Janeiro, v. 5, p. 10, 31 dez., 1932.

. Constituição (1934). Constituição da República dos Estados Unidos do Brasil. Diário Oficial [da] união, Poder Legislativo, Rio de Janeiro, p. 1, 16 jul., 1934.

. Constituição (1988). Constituição da República Federativa do Brasil, de 05 de outubro de 1988. Diário Oficial [da] União, Poder Legislativo, n.191-A, 05 out., 1988.

. Lei $n^{\circ}$ 8069, de 13 de julho de 1990. Dispõe sobre o Estatuto da Criança e do Adolescente e dá outras providências. Diário oficial [da] União, poder Executivo. Brasília, DF, 16 jul., 1990.

Coracini, M. José R. F. A escamoteação da heterogeneidade. In Coracini, M. José R. F.; Bertoldo, Ernesto S. (Orgs). O desejo da teoria e a contingência da prática. Discursos sobre e na sala de aula. Campinas: Mercado das Letras, 2003, p. 251-270.

Courtine, Jean-Jacques. Définition d'Orientations Théoriques et Méthodologiques en Analyse de Discours. In: Philosophiques, vol. IX. n.2, Paris, 1984. . Metamorfoses do discurso político: as derivas da fala pública. Trad. Nilton Milanez e Carlos Piovezani Filho. São Carlos: Claraluz, 2006.

Custódio, André V. A exploração do trabalho infantil doméstico no Brasil contemporâneo: limites e perspectivas para sua erradicação. Florianópolis: UFSC, 2006. Tese (Curso de Pós-Graduação em Direito), Universidade Federal de Santa Catarina, 2006.

Deleuze, Gilles. Post scriptum sobre as sociedades de controle. In. Deleuze, Gilles. Conversações. Rio de Janeiro: 34 Letras, 1992, p. 219-26.

Del Priore, Mary. (org.) História das crianças no Brasil. 5. ed. São Paulo: Contexto, 2006. 
Fonseca-Silva, Maria da C. Mídia e lugares de memória discursiva. In: Mídia e rede de memória. Fonseca-Silva, Maria da C. e Possenti, Sírio. (Orgs.). Vitória da Conquista: Uesb, 2007, p. 11-37.

Foucault, Michel. História da Sexualidade I: A Vontade de Saber. Trad. Maria Thereza da Costa Albuquerque e J. A. Guilhon Albuquerque. Rio de Janeiro: Graal, 1977.

A arqueologia do saber. Trad. Luiz Felipe Baeta Neves. São Paulo: Forense, 2002.

Gregolin, M. do Rosário Valencise. Discurso, história e a produção de identidades na mídia. In: Mídia e rede de memória. Fonseca-Silva, Maria da Conceição e PossentI, Sírio. (Orgs.). Vitória da Conquista: Uesb, 2007, p. 39-60. Guerra, Vânia M. L. A violência, o poder e a memória na construção do discurso midiático. In Guerra,Vânia M. L. Práticas discursivas: crenças, estratégias e estilos. São Carlos: Pedro \& João Editores, 2008, p. 111-122.

Hall, Stuart. A centralidade da cultura: notas sobre as revoluções de nosso tempo. In Educação e Realidade, Porto Alegre, v. 22, n. 2, 1997, p. 15-46.

Jameson, Fredric. Pós-modernismo: a lógica cultural do capitalismo tardio. Trad. Maria Elisa Cevasco. 2 ed. São Paulo: Ática, 2002.

Moura, Esmeralda B. B. de. Crianças operárias na recém industrializada São Paulo. In: Del Priore, Mary. (org.). História das crianças no Brasil. São Paulo: Contexto, 2006, p. 259-28.

Orlandi, Eni P. Segmentar ou recortar? In: Guimarães, Eduardo. (org.) Lingüística: questões e controvésias. Série Estudos, n.10. Uberaba: Fiube, 1984. Passetti, Edson. Crianças carentes e políticas públicas. In: Del Priore, Mary. (org.). História das crianças no Brasil. 5. ed. São Paulo: Contexto, 2006, p. 347-75.

Pêcheux, Michel. O Discurso: estrutura ou acontecimento. Trad. Eni P. Orlandi. 3. ed. Campinas: Pontes, 2002.

Postman, Neil. O desaparecimento da infância. Trad. Suzana M. de A. Carvalho e José L. de Melo. Rio de Janeiro: Graphia, 1999.

Ramos, Fábio A história trágico-marítima das crianças nas embarcações portuguesas do século XVI. In: Del Priore, Mary. (org.) História das crianças no Brasil. São Paulo: Contexto, 2006, p.19-54.

Rizzini, Irma. Pequenos trabalhadores do Brasil. In: Del Priore, Mary. (org.) História das crianças no Brasil. São Paulo: Contexto, 2006, p. 376-406. 